\title{
Pengaruh Penggunaan Media Pembelajaran Google Meet Terhadap Motivasi Belajar Siswa Madrasah Tsanawiyah
}

\author{
M. Arifky Pratama ${ }^{1 *}$, Yetri Pitriani ${ }^{1}$ \\ ${ }^{1}$ MTsN 1 Bengkulu Selatan \\ *Email: arifkypratama95@gmail.com
}

\begin{tabular}{|c|c|}
\hline Info Artikel & Abstrak \\
\hline $\begin{array}{l}\text { Diterima: } 12 \text { September } 2021 \\
\text { Direvisi: } 29 \text { Oktober } 2021 \\
\text { Diterima: } 3 \text { November } 2021 \\
\text { untuk diterbitkan: }\end{array}$ & $\begin{array}{l}\text { Penelitian ini bertujuan untuk mengetahui pengaruh media } \\
\text { pembelajaran Google Meet terhadap motivasi siswa MTsN } 1 \\
\text { Bengkulu Selatan. Metode penelitian ini menggunakan desain } \\
\text { eksperimen semu (quasi experiment) dengan desain penelitian } \\
\text { berupa Non-Randomized Control-Group Pretest-Posttest }\end{array}$ \\
\hline $\begin{array}{l}\text { Keywords: } \\
\text { Google Meet, Motivasi Belajar }\end{array}$ & $\begin{array}{l}\text { Design. Quasi eksperimental design mempunyai kelompok } \\
\text { kontrol, tetapi tidak dapat berfungsi sepenuhnya untuk } \\
\text { mengontrol variabel-variabel luar yang mempengaruhi } \\
\text { pelaksanaan eksperimen. Teknik analisis data penelitian ini } \\
\text { menggunakan uji normalitas One-Sample Kolmogorov- } \\
\text { Smirnov, yang selanjutnya diuji homogenitasnya menggunakan } \\
\text { Levene Statistic, setelah diketahui data berdistribusi normal dan } \\
\text { homogen, dilakukan uji analisis datanya menggunakan uji T. } \\
\text { Pada kelas eksperimen dan kelas kontrol ditemukan beberapa } \\
\text { permasalahan, di antaranya keterbatasan fasilitas dan jaringan } \\
\text { internet pada siswa yang berada di desa pedalaman. Hasil } \\
\text { penelitian menunjukkan bahwa nilai rata-rata motivasi belajar } \\
\text { pada kelas eksperimen adalah } 74,97 \text {, sedangkan pada kelas } \\
\text { kontrol adalah } 69,74 \text {. Adapun nilai p-value yang diperoleh } \\
\text { adalah sebesar } 0,000 \text {. Dapat ditarik sebuah kesimpulan bahwa } \\
\text { penggunaan media pembelajaran Google Meet secara } \\
\text { signifikan berpengaruh terhadap motivasi siswa dari pada } \\
\text { pembelajaran menggunakan media pembelajaran Whatsapp. }\end{array}$ \\
\hline
\end{tabular}

(C) 2021 Universitas Bengkulu. This is an open-access article under the CC-BY license (https://creativecommons.org/licenses/by/4.0)

\section{PENDAHULUAN}

Pendidikan merupakan suatu proses pembentukan diri yang dilakukan individu secara sadar dan berkelanjutan untuk mendapatkan pembentukan diri yang berkualitas. Pendidikan merupakan suatu usaha yang dilakukan secara terencana sistematis dan logis dalam rangka membina manusia dalam proses pendewasaan sesuai dengan kebutuhan dan tuntutan hidup di lingkungannya (Putri \& 
Dewi, 2019). Menurut Syukri et.al (2019) pendidikan merupakan persoalan hidup manusia sepanjang hayatnya baik sebagai individu, kelompok sosial, maupun sebagai bangsa.

Dengan adanya pendidikan, diharapkan dapat merubah kehidupan anak bangsa yang memiliki jiwa berkarakter dan berdaya saing. Hal ini sejalan dengan pendapat yang mengatakan bahwa pendidikan merupakan suatu kebutuhan manusia yang sangat penting karena dengan pendidikan dapat menciptakan manusia yang berkualitas dan berkarakter yang memiliki wawasan luas sehingga dapat mencapai suatu cita-cita yang diharapkan (Niswara et al., 2019). Sejalan dengan hal itu, terdapat pendapat yang mengatakan bahwa tujuan pendidikan adalah menciptakan manusia berkualitas dan berkarakter sehingga memiliki pengetahuan yang luas ke depan untuk mencapai suatu cita-cita yang diharapkan dan mampu beradaptasi secara cepat dan tepat di berbagai lingkungan karena pendidikan itu sendiri memotivasi diri kita untuk lebih baik dalam segala aspek kehidupan (Yuniarti, 2017). Undang-undang yang menyebutkan bahwa pendidikan adalah usaha sadar dan terencana untuk mewujudkan suasana belajar dan proses pembelajaran agar peserta didik secara aktif mengembangkan potensi dirinya untuk memiliki kekuatan spiritual keagamaan, pengendalian diri, kepribadian, kecerdasan, akhlak mulia, serta keterampilan yang diperlukan dirinya di masyarakat (UU SISDIKNAS No. 20 tahun 2003).

Mendapatkan kualitas peserta didik yang demikan tentu harus didukung dengan peran guru dalam pembelajaran, salah satunya penggunaan media pembelajaran yang tepat dan menyenangkan. Sejalan dengan hal itu, salah satu media pembelajaran yang dapat digunakan untuk meningkatkan motivasi belajar peserta didik melaui Google Meet. Media pembelajaran ini mengharuskan penguasaan teknologi bagi peserta didik. Melalui media Google Meet ini, pembelajaran dilangsungkan secara virtual, pembelajaran dilakukan seperti di dalam kelas, yaitu tatap muka namun pada media ini tatap muka dalam layar, dalam artian pembelajaran tatap muka secara online atau virtual. Penggunaan media yang bervariatif dianggap dapat meningkatkan motivasi belajar siswa agar terhindar dari kejenuhan. Oleh karena itu, media pembelajaran sebagai suatu upaya meningkatkan motivasi belajar peserta didik, yaitu digunakan media pembelajaran yang baik dan benar, serta menarik (Febrita et.al, 2019). Sejalan hal itu, terdapat pendapat yang mengatakan bahwa dengan munculnya motivasi belajar peserta didik maka mereka akan memiliki motivasi belajar tinggi lebih sadar akan pentingnya belajar sehingga lebih siap untuk menerima materi yang disampaikan oleh pendidik (Widiyanti, 2020).

Terdapat beberapa manfaat penggunaan media pembelajaran, di antaranya (1) pembelajaran akan lebih menarik perhatian siswa sehingga dapat menumbuhkan motivasi belajar; (2) bahan pertimbangan akan lebih jelas maknanya, sehingga dapat lebih dipahami oleh siswa dan memungkinkannya menguasai dan mencapai tujuan pembelajaran; (3) metode mengajar akan lebih bervariasi, tidak semata-mata komunikasi verbal melalui penuturan kata-kata oleh guru, sehingga siswa tidak bosan dan guru tidak kehabisan tenaga; (4) siswa dapat lebih banyak melakukan kegiatan belajar sebab tidak hanya mendengarkan uraian guru, tetapi juga aktivitas lain seperti mengamati, melakukan, mendemontrasikan, memerankan, dan lain-lain (Arsyad, 2013). Terdapat beberapa jenis motivasi menurut Ernata (2017), yaitu motivasi belajar intrinsik dan motivasi belajar ekstrinsik. Motivasi belajar intrinsik adalah motif-motif yang menjadi aktif atau berfungsinya tidak perlu rangsangan dari luar karena dalam diri setiap individu sudah ada dorongan untuk melakukan sesuatu. Sedangkan motivasi ekstrinsik adalah motif-motif yang aktif dan berfungsinya karena adanya rangsangan dari luar.

Dari uraian manfaat penggunaan media pembelajaran tersebut dapat disimpulkan bahwa penggunaan media pembelajaran sangat efektif dalam penyampaian materi pembelajaran. Kegiatan pembelajaran yang variatif, mengurangi verbalisme, meningkatkan motivasi peserta didik sehingga dapat mencapai tujuan pendidikan, yang mendapatkan hasil akhir peserta didik yang berkualitas. Peran penting dalam mencapai tujuan pembelajaran adalah motivasi yang tumbuh dalam diri peserta didik. Dengan adanya motivasi, maka peserta didik akan tertarik dan terdorong untuk mengikuti pembelajaran secara maksimal. Sejalan dengan hal itu, motivasi adalah serangkaian usaha untuk menyediakan kondisi-kondisi tertentu sehingga sesorang mau dan ingin melakukan 
sesuatu dan bila tidak suka maka akan berusaha meniadakan atau mengelakkan perasaan tidak suka (Pratama \& Irwandi 2021).

Berdasarkan hasil UAS semester genap tahun pelajaran 2020/2021 mata pelajaran IPA siswa kelas VIII MTsN 1 Bengkulu Selatan masih banyak siswa yang mendapatkan nilai di bawah KKM (70) sekitar $65 \%$. Kasus ini dipicu dengan kurangnya motivasi peserta didik dalam belajar, hal ini dapat dilihat pada saat pembelajaran berlangsung masih ada beberapa siswa yang tidak terpusat pada pembelajaran, tidak memiliki motivasi untuk belajar, sehingga tidak mendapatkan hasil yang maksimal. Sarana dan Prasana dalam tekhnologi yang terdapat di MTsN 1 Bengkulu Selatan sudah cukup memadai untuk kepentingan pembelajaran, hanya saja belum dimanfaatkan secara efektif dan efisien. Kurangnya motivasi belajar siswa juga dipicu dari minimnya penggunaan media pembelajaran yang digunakan guru, sehingga tidak memunculkan ketertarikan siswa dalam belajar. Hal ini diperlukan perubahan dan peningkatan motivasi belajar, seperti dengan memanfaatkan fasilitas madrasah menjadi media pembelajaran yang sesuai dan menarik, sehingga dapat memicu meningkatnya motivasi belajar siswa.

Berdasarkan uraian di atas mengenai pengaruh media pembelajaran Google Meet terhadap motivasi belajar siswa, maka diperlukan suatu kajian dan pembahasan untuk melihat pengaruh media pembelajaran khususnya untuk meningkatkan motivasi belajar siswa. Oleh karena itu, peneliti melakukan kajian untuk menganalisis Pengaruh Media Pembelajaran Google Meet terhadap Motivasi Belajar Siswa Madrasah Tsanawiyah.

\section{METODE}

Penelitian ini dilaksanakan pada bulan 03 sampai dengan 31 Agustus 2021 di kelas IX A (eksperimen) dan IX B (kontrol). Jenis penelitian yang digunakan yaitu eksperimen semu (quasi experiment) dengan desain penelitian berupa Non-Randomized Control-Group Pretest-Posttest Design. Quasi eksperimental design mempunyai kelompok kontrol, tetapi tidak dapat berfungsi sepenuhnya untuk mengontrol variabel-variabel luar yang mempengaruhi pelaksanaan eksperimen. Kelas eksperimen dan kelas kontrol diberikan materi yang sama dengan media pembelajaran yang berbeda. Kelas eksperimen menggunakan media pembelajaran Google Meet, sedangkan kelas kontrol menggunakan media Whatsapp.

Variabel dalam penelitian ini terdiri dari variabel bebas (X) yakni Google Meet, sedangkan variabel terikat (Y) adalah motivasi. Populasi pada penelitian ini adalah siswa kelas IX MTsN 1 Bengkulu Selatan yang terdiri dari 4 kelas dengan jumlah seluruh siswa yaitu 82 siswa.

Teknik pengambilan sampel yang digunakan dalam penelitian ini adalah Purposive Sampling, karena sampel ditentukan sendiri sesuai pertimbangan tertentu dari guru mata pelajaran dan kepala madrasah, yang dalam hal ini sampel terdiri dari 2 kelas yaitu IX A (eksperimen) dan kelas IX B (kontrol). Dimana dalam penelitian ini, kelas eksperimen IX A berjumlah 26 orang yang kegiatan pembelajarannya dilakukan melalui media pembelajaran Google Meet, sedangkan kelas kontrol IX B berjumlah 26 orang dilakukan melalui media pemebelajaran Whatsapp.

Teknik analisis data penelitian ini menggunakan uji normalitas One-Sample KolmogorovSmirnov yang selanjutnya diuji homogenitasnya menggunakan Levene Statistic, setelah diketahui data berdistribusi normal dan homogeny, dilakukan uji analisis datanya menggunakan uji T.

Pengambilan data motivasi dilakukan dengan cara memberikan seperangkat pertanyaan tertulis secara langsung kepada responden untuk dijawab. Adapun responden dalam penelitian ini yaitu siswa kelas IX A (eksperimen) dan kelas IX B (kontrol) MTsN 1 Bengkulu Selatan. Setelah data terkumpul, maka data selanjutnya akan dianalisis tingkat motivasi siswa. Angket yang digunakan mengacu kepada angket motivasi belajar siswa yang diadopsi dan dimodifikasi dari Tuan et al., (2005) terdiri atas 25 butir pertanyaan.

\section{HASIL DAN PEMBAHASAN}

Penelitian ini dilaksanakan pada tanggal 03 sampai dengan 31 Agustus 2021. Untuk memperoleh data penelitian, telah diberikan seperangkat pertanyaan atau kuisioner kepada peserta 
didik yang menjadi responden dalam penelitian ini secara langsung untuk dijawab sesuai keadaan dan situasi yang dialami. Adapun Hasil data angket motivasi belajar siswa adalah sebagai berikut:

\section{Tabel 1}

Hasil Skor Motivasi Belajar Siswa

\begin{tabular}{lcc}
\hline \multirow{2}{*}{ Perhitungan } & \multicolumn{2}{c}{ Motivasi Belajar } \\
\cline { 2 - 3 } & Eksperimen & Kelas kontrol \\
\hline Jumlah skor & 2374 & 1467 \\
Skor tertinggi & 92 & 83 \\
Skor terendah & 84 & 71 \\
\hline Rata-rata & 74,97 & 69,74 \\
\hline
\end{tabular}

Berdasarkan tabel 1 dapat diketahui rata-rata motivasi belajar siswa pada kelas eksperimen adalah sebesar 74,97 dengan skor tertinggi 92 dan skor terendah sebesar 83, sedangkan pada kelas kontrol rata- rata motivasi belajar adalah 69,74 dengan skor tertinggi 83 dan skor terendah 71 . Berdasarkan data tersebut, dapat disimpulkan bahwa rata-rata motivasi belajar kelas eksperimen yang menggunakan media pembelajaran Google Meet lebih tinggi dibandingkan dengan kelas kontrol yang menggunakan media pembelajaran WhatsApp.

\section{Tabel 2}

Uji Normalitas Data Motivasi Belajar Siswa

\begin{tabular}{llr}
\hline & One-Sample Kolmogorov-Smirnov Test 2 & Unstandardized Residual \\
\hline $\mathrm{N}$ & & $25^{\mathrm{c}}$ \\
\hline Exponential parameter. ${ }^{\mathrm{a}, \mathrm{b}}$ & Mean & 3.740522 \\
\hline & Absolute & .063 \\
Most Extreme Differences & Positive & .063 \\
& Negative & -.051 \\
\hline Kolmogorov-Smirnov Z & & .071 \\
\hline Asymp. Sig. (2-tailed) & & .138 \\
\hline
\end{tabular}

Berdasarkan Tabel 2 menunjukkan bahwa kelas eksperimen dan kelas kontrol dengan nilai sig. 0,138 lebih besar dari 0,05, artinya data angket motivasi berdistribusi normal.

\section{Tabel 3}

Uji Homogenitas Data Motivasi Belajar Siswa

\begin{tabular}{cccc}
\hline Levene Statistic & df1 & df2 & Sig. \\
\hline 1.258 & 5 & 12 & .184 \\
\hline
\end{tabular}

Berdasarkan Tabel 3 dapat dilihat signifikan sebesar 0,184 yang artinya lebih besar dari 0,05, sehingga dapat disimpulkan data angket motivasi belajar mempunyai varian yang homogen.

\section{Tabel 4}

Uji t Data Motivasi Belajar Siswa

\begin{tabular}{lcc}
\hline \multirow{2}{*}{ t-test for Equality of Means } & \multicolumn{2}{c}{ Motivasi Belajar Siswa } \\
\cline { 2 - 3 } & Equal variances assumed & Equal variances not assumed \\
\hline T & 22.108 & 22.108 \\
\hline Df & 60 & 47.988 \\
\hline Sig. (2-tailed) & .000 & .000 \\
\hline
\end{tabular}


Berdasarkan Tabel 4 dapat dilihat data motivasi belajar siswa diperoleh nilai sig (2 tailed) atau p value sebesar 0,000 lebih kecil dari 0,05 $(0,000<0,05)$, hal ini berarti terdapat perbedaan motivasi belajar siswa dalam pembelajaran IPA antara kelas eksperimen dan kelas kontrol yang mengunakan media pembelajaran yang berbeda dalam pelaksanaannya. Pada penelitian berlangsung, kelas eksperimen menggunakan media Google Meet, sedangkan kelas kontrol menggunakan media Whatsapp.

\section{Tabel 5}

Motivasi Siswa Kelas Eksperimen (Google Meet)

\begin{tabular}{lcc}
\hline \multicolumn{1}{c}{ Kriteria } & Frekuensi & Persentase \\
\hline Sangat Tinggi (90-100) & - & - \\
\hline Tinggi (70-89) & 21 & $83,87 \%$ \\
\hline Cukup (60-69) & 4 & $16,13 \%$ \\
\hline Rendah (50-59) & - & - \\
\hline Sangat Rendah (40-49) & - & - \\
\hline
\end{tabular}

\section{Tabel 6}

Motivasi Siswa Kelas Kontrol (Whatsapp)

\begin{tabular}{|c|c|c|}
\hline Kriteria & Frekuensi & Persentase \\
\hline Sangat Tinggi (90-100) & - & - \\
\hline Tinggi (70-89) & - & - \\
\hline Cukup (60-69) & - & - \\
\hline Rendah (50-59) & 25 & $100 \%$ \\
\hline Sangat Rendah (40-49) & - & - \\
\hline
\end{tabular}

Berdasarkan hasil analisis pada tabel 5 dan 6 di atas, motivasi belajar siswa kelas eksperimen (IX A) diperoleh 21 orang siswa $(83,87 \%)$ dengan kriteria motivasi belajar tinggi, 4 orang siswa (16,13\%) dengan kriteria cukup. Sedangkan motivasi belajar siswa kelas kontrol (IX B) pada tabel 6 , yaitu 25 orang siswa $(100 \%)$ dengan kriteria motivasi belajar rendah. Berdasarkan data motivasi belajar siswa dari kedua kelas tersebut dapat disimpulkan bahwa motivasi belajar siswa kelas eksperimen (IX A) secara persentase lebih tinggi dibandingkan kelas kontrol (IX B). Pada kelas eksperimen dan kelas kontrol ditemukan beberapa permasalahan, di antaranya keterbatasan fasilitas dan jaringan internet pada siswa yang berada di desa pedalaman.

Keberhasilan penggunaan media pembelajaran Google Meet dikarenakan Google Meet bisa menjadi media alternatif untuk proses belajar mengajar, bersosialisasi dengan rekan kantor, atau bahkan melakukan rapat kerja dari dalam rumah. Google meet memungkinkan pengguna untuk melakukan panggilan video dengan 25 pengguna lainnya per pertemuan. Kelebihan dari Google Meet adalah 1) Adanya fitur White Board, 2) Tersedia Gratis, 3) Tampilan video yang HD dan support resolusi lain, 4) Mudah penggunaanya, 5) Layanan Enkripsi video, 6) Banyak pilihan tampilan yang menarik (Aisyah \& Sari, 2021).

Motivasi belajar merupakan faktor penting yang menentukan keberhasilan siswa dalam belajar. Sementara itu, dalam modus pembelajaran daring yang saat ini harus dilaksanakan agar peserta didik memiliki pengalaman belajar yang tidak jauh berbeda dengan pembelajaran tatap muka di kelas, maka perlu dilaksanakan sesi tatap maya (virtual synchronous). Fungsi motivasi adalah sebagai pendorong usaha dalam mencapai prestasi, karena seseorang melakukan usaha harus mendorong keinginannya dan menentukan arah perbuatannya ke arah tujuan yang hendak dicapai. Dengan demikian, siswa dapat menyeleksi perbuatan untuk menentukan apa yang harus dilakukan yang bermanfaat bagi tujuan yang hendak dicapainya (Pratama \& Irwandi, 2021).

Berdasarkan penelitian yang dilakukan oleh Hasanah et al., (2021) Google Meet dapat meningkatkan motivasi belajar siswa dikarenakan memiliki interface atau antarmuka yang unik dan fungsional dengan ukuran ringan serta cepat, mengedepankan pengelolaan yang efisien, mudah guna (user friendly) yang dapat diikuti semua pesertanya. Sejalan dengan hasil penelitian Huda et 
al., (2022) penerapan media Google Meet dapat meningkatkan motivasi belajar siswa, hal ini dapat dilihat dari meningkatnya keaktifan siswa dalam pembelajaran. Hasil nilai rata-rata keaktifan siswa pada siklus I, yakni 3,17 dan masuk dalam kategori baik, sedangkan pada siklus II nilai rata-rata keaktifan siswa meningkat menjadi 3,53 dengan kategori sangat baik.

Google Meet dapat digunakan sebagai salah satu media pembelajaran yang dapat menunjang proses pembelajaran siswa yang berlangsung dari rumah sekaligus mengajarkan siswa untuk memanfaatkan teknologi sejak dini, sehingga dapat memberikan pengalaman yang bermakna untuk siswa tersebut. Pemanfaatan Google Meet sebagai media pembelajaran bertujuan untuk menciptakan keterampilan menyimak dan berbicara dalam menggunakan aplikasi Google Meet sebagai media pembelajaran (Juniartini \& Rasna, 2020).

Angka penggunaan Google Meet hariannya meningkat 25 kali lipat dalam periode antara bulan Januari hingga Maret 2020. Google Meet menjadi versi yang lebih kuat dibanding Hangouts pendahulunya karena Google Meet mampu ditampilkan pada aplikasi web, aplikasi Android, dan iOS. Maka dari itu, banyak yang mencari alternatif dengan menggunakan berbagai (Muniroh et al, 2020).

\section{KESIMPULAN}

Dari penelitian yang telah dilakukan mengenai Pengaruh Media Pembelajaran Google Meet terhadap Motivasi Belajar Siswa Madrasah Tsanawiyah maka dapat ditarik kesimpulan bahwa penggunaan media pembelajaran Google Meet dapat meningkatkan motivasi belajar. Hasil penelitian menunjukkan bahwa nilai rata-rata motivasi belajar pada kelas eksperimen adalah 74,97, sedangkan pada kelas kontrol adalah 69,74. Adapun nilai p-value yang diperoleh adalah sebesar 0,000. Simpulannya, penggunaan media pembelajaran Google Meet secara signifikan berpengaruh terhadap motivasi siswa dari pada pembelajaran menggunakan media pembelajaran Whatsapp.

\section{UCAPAN TERIMA KASIH}

Kami ucapkan terimakasih kepada Kantor Kementerian Agama Kabupaten Bengkulu Selatan khususnya MTsN 1 Bengkulu Selatan yang sudah mendukung dan memfasilitasi penelitian ini, sehingga penelitian ini berjalan dengan lancar.

\section{DAFTAR PUSTAKA}

Aisyah, S., \& Sari, D. I. (2021). Efektifitas Penggunaan Platform Google Meet Terhadap Hasil Belajar Siswa. JURNAL MathEdu (Mathematic Education Journal). 4 (1). https://doi.org/10.37081/mathedu.v4i1.2313.

Arsyad, Azhar. (2013). Media Pembelajaran. Jakarta: Rajagrafindo Persada.

Ernata, Y. (2017). Analisis Motivasi Belajar Peserta Didik Melalui Pemberian Reward dan Punishment di SDN Ngaringan 05 Kec. Gandusari, Kab. Blitar. Jurnal Pemikiran dan Pengembangan Sekolah Dasar (JP2SD), 5(2), 781-790.

Febrita, Yolanda., \& Ulfah, Maria. (2019). Peranan Media Pembelajaran Untuk Meningkatkan Motivasi Belajar Siswa. Diskusi Panel Nasional Pendidikan Matematika. 5. ISSN 25810812. http://proceeding.unindra.ac.id/index.php/DPNPMunindra/article/view/571.

Juniartini, N. M. E., \& Rasna, I. W. (2020). Pemanfaatan Aplikasi Google Meet Dalam Keterampilan Menyimak dan Berbicara Untuk Pembelajaran Bahasa Pada Masa Pandemi Covid-19. Jurnal Pendidikan dan Pembelajaran Bahasa Indonesia, 9(2), 133-141.

Hasanah, M. H., Wulandari, A. A., \& Rusidah, N. (2021). Google Meet dalam Pembelajaran Matematika untuk Meningkatkan Motivasi Belajar Siswa Kelas XII IPS-3 SMAN 2 
tawangsari. JP2M (Jurnal Pendidikan dan Pembelajaran Matematika), 7(1), 1-9. https://www.jurnal.stkippgritulungagung.ac.id/index.php/jp2m/article/view/1828.

Huda, A. N., Siwi, D. A., \& Rahayu, C. P. (2022). Peningkatan Motivasi dan Hasil Belajar IPA melalui Penerapan Google Meet pada Siswa Sekolah Dasar. Educatif Journal of Education Research, 4(3), 9-16.

Pratama, M. A., \& Irwandi. (2021). Efektifitas Model Pembelajaran PjBL Melalui Google Form Terhadap Motivasi Belajar Siswa MTs. BIOEDUSAINS: Jurnal Pendidikan Biologi dan Sains, 4(2),

186. https://journal.ipm2kpe.or.id/index.php/BIOEDUSAINS/article/view/2505.

Muniroh, S. H., Rojanah, S., \& Raharjo, S. (2020). Efektivitas Pembelajaran Matematika Melalui Media Google Meet Ditinjau Dari Hasil Belajar Siswa Di Masa Pandemi Covid19. EDISI, 2(2), 410-419.

Niswara, R., Fita, M., \& Untari, A. (2019). Pengaruh Model Project Based Learning terhadap High Order Thingking Skill. Mimbar PGSD Undiksha, 7(2), 86. https://ejournal.undiksha.ac.id/ index.php/JJPGSD/article/view/17493.

Putri, G. K., \& Dewi, S.A.Y. (2019). Pengaruh Model Pembelajaran Jarak Jauh Berbasis Google Classroom Efect of Google Classroom-Based Distance Learning Model. Al-Fikrah, 2(1), 60-79. https://ejournal.undiksha.ac.id/index.php/JJPGSD/article/view/17493.

Syukri, I. I. F., Rizal, S. S., \& Al Hamdani, M. D. (2019). Pengaruh Kegiatan Keagamaan Terhadap Kualitas Pendidikan. Jurnal Penelitian Pendidikan Islam,[SL], 7(1), 17-34.

Tuan, H. L., Chin, C. C., \& Shieh, S. H. (2005). The development of a questionnaire to measure students' motivation towards science learning. International journal of science education, 27(6), 639-654.

UU SISDIKNAS No. 20 tahun 2003. https://peraturan.bpk.go.id/Home/Details/43920/uu-no-20tahun-2003.

Widiyanti, N., \& Ansori, Y. Z. (2020). Pengaruh Media Pembelajaran Terhadap Motivasi Belajar Siswa Kelas V di SDN Ciparay I Tahun Ajaran 2020/2021. Seminar Nasional Pendidikan , FKIP UNMA. https://prosiding.unma.ac.id/index.php/semnasfkip/article/view/325.

Yunarti, Y. (2017). Pendidikan ke Arah Pembentukan Karakter. Tarbawiyah: Jurnal Ilmiah Pendidikan, 11(02), 262-278. 